Linha D'Água (Online), São Paulo, v. 30, n. 1, p. 69-87, jun. 2017

\title{
O PODER DOS DISCURSOS DO PATRONATO PORTUENSE NAS SESSÕES COMEMORATIVAS DE ANIVERSÁRIOS: RITUAIS VERBAIS, ARGUMENTAÇÃO E CONFIGURAÇÃO ENUNCIATIVA
}

\author{
THE POWER OF THE SPEECHES OF PORTO'S EMPLOYERS IN \\ ANNIVERSARY COMMEMORATIVE SESSIONS: VERBAL RITUALS, \\ ARGUMENTATION AND ENUNCIATIVE CONFIGURATION
}

Carla Aurélia de Almeida*
Universidade do Porto, Porto, Portugal

Resumo: Tendo por base um corpus de noticicas com os discursos de aniversário da Associação Industrial Portuense publicados na revista A Indústria do Norte (1949-1970), procederemos à análise do modo como, nestes discursos, se estrutura uma imagem do locutor. Para o efeito, consideramos a organização enunciativa do discurso comemorativo de aniversário, as sequências de atos de discurso e as estratégias discursivas de intensificaçã̃o e de mitigacạ̃o ao serviço da persuasão. Verificaremos que os representantes dos patrões põem em jogo um dispositivo argumentativo de convocacã̃o de uma doxa partihada pela comunidade de discurso. Esta estratégia de argumentacạão é reveladora de uma tomada de posição espećfica de um locutor representativo do patronato portuense.

Palavras-chave: Estratégias discursivas; Patronato portuense; Mitigadores; Intensificadores; Argumentação.

\begin{abstract}
Taking as a basis a corpus of news with the anniversary speeches of the Associação Industrial Portuense published in the news magazine A Indústria do Norte (1949-1970), we will analyse how, in those speeches, an image of the speaker is structured. For this purpose, we will consider the enunciative organisation of the commemorative speech for the anniversary; the speech acts sequence and the discursive strategies of intensification and mitigation at the service of persuasion. We will verify that the representatives of the employers put at steak a covening argumentative instrument of a doxa shared by a speech community. This strategy of argumentation is revealing and has to do with a specific position-taking of a representative speaker from Porto's employers.
\end{abstract}

Keywords: Discursive Strategies; Porto's Employers; Mitigators; Intensifiers; Argumentation.

* Professora Auxiliar do Departamento de Humanidades da Universidade Aberta - UAb; investigadora do Instituto de Sociologia da Universidade do Porto - UP, Porto, Portugal; calmeida@uab.pt 
Linha D'Água (Online), São Paulo, v. 30, n. 1, p. 69-87, jun. 2017

\section{Introdução}

O enfoque teórico e metodológico deste trabalho é orientado por uma perspetiva semântico-pragmática (VERSCHUEREN, 1998, p. 236) da organização e funcionamento de quatro discursos proferidos nos aniversários da Associação Industrial Portuense publicados na revista $A$ Indústria do Norte (1949-1970). Procederemos à análise do modo como, nestes discursos, se constrói uma imagem dos "homens industriosos" (Monteiro, 2015), considerando a organização enunciativa do discurso comemorativo de aniversário: analisaremos o quadro interacional (GOFFMAN, 1987) construído nas sessões comemorativas, consideraremos a sequência de atos de discurso, as estratégias discursivas que estes atos configuram e estudaremos o rumo discursivo ou discursivização (FONSECA, 1992, p. 316) que os enunciados proferidos determinam. Verificaremos que, nestes discursos de comemoração de aniversários da AIP, os representantes dos patrões põem em funcionamento um dispositivo argumentativo de convocação de uma doxa partilhada pela comunidade de discurso (GUMPERZ, 1989), característica de uma tomada de posição ideológica (MONTEIRO, 2015, p. 134), específica de um locutor representativo do patronato portuense do período histórico em questão.

Procuraremos demonstrar, por fim, que o discurso nestes contextos comemorativos apresenta a realização de atos de elogio que visam a manutenção de uma ordem institucional.

\section{Alguns pressupostos analíticos: o discurso de comemoração e o poder instituído no corpus delimitado}

No presente texto, consideraremos um corpus de notícias publicadas numa revista representativa de uma época e de uma região do Norte de Portugal. Analisaremos, para o efeito, a organização e o funcionamento de quatro notícias com a reprodução dos discursos proferidos nos aniversários da AIP publicados na revista $A$ Indústria do Norte (1949-1970): especificamente, as notícias relativas ao $101 .^{\circ}$ aniversário (1950), ao $105 .^{\circ}$ (1954), ao $106 .^{\circ}$ (1955) e ao $115 .^{\circ}$ (1964).

Estamos perante discursos que revelam relações de poder instituídas no e através dos discursos de comemoração, demonstrando uma clara diferenciação 
Linha D'Água (Online), São Paulo, v. 30, n. 1, p. 69-87, jun. 2017

de posiçôes interacionais (GOFFMAN, 1987) ou lugares ${ }^{1}$ (KERBRAT-ORECCHIONI, 1988, p. 186) que condicionam o quadro de participação (GOFFMAN, 1987) $)^{2}$. Os locutores posicionam-se em relação aos outros na interação, revelando que seguem normas morais implícitas provindas do contexto social e cultural alargado (WORTHAM e LOCHER, 1996, p. 557). Com efeito, qualquer discurso dos atores cria "posições subjetivas": "O próprio ato de falar implica falar a partir de um posicionamento" (WETHERELL et al., 2001, p. 23; tradução própria).

Nestes contextos de discursos de comemoração, verificamos a ocorrência de regularidades discursivas reveladoras de uma visão particular do mundo relativamente à relação com a fábrica e os operários, uma visão que poderemos considerar como característica e representativa do patronato portuense deste período (MONTEIRO, 2015, p. 59).

Os discursos de aniversário em apreço visam efeitos de poder (FOUCAULT, 1994, p. 233) $)^{3}$, apresentando "significados e poderes historicamente determinados" (MONTEIRO, 2015, p. 61). Os discursos patronais assim constituídos configuram-se como reveladores dos estilos dos patrões (ou dirigentes empresariais) portuenses: 1. o patrão como "pai” (ou "chefe"); 2. o patrão como técnico (um profissional) - o patrão "engenheiro", como a personificação de um sujeito económico - “o

1 A noção de lugar está intimamente ligada à noção de footing ou alinhamento dos participantes, noção referida por Goffman (1987). Segundo este autor, o "alinhamento dos participantes" e/ou projeção de segmentos discursivos possibilita a ordem interacional: "Recomendava-se que se conseguiria determinar a base estrutural dos alinhamentos ('footing') ao desmembrar as noções primitivas de ouvinte e falante em partes mais diferenciadas, nomeadamente, em enquadramento de participação e formato de produção" (Goffman, 1987, itálicos nossos).

2 Sobre a noção de "quadro de participação", cf. a seguinte afirmação de Goffman (1987): "Depois, há 'o quadro de participação'. Cada vez que uma palavra é pronunciada, todos aqueles que se encontram à disposição do acontecimento possuem, em relação a ele, um certo estatuto de participação. A codificação destas diversas posições e a especialização normativa do que constitui uma conduta conveniente no seio de cada uma constituem um plano subjacente essencial para a análise da interação - na nossa sociedade como (eu suponho) em toda a outra" (Idem: 9; tradução própria).

3 Cf. a seguinte afirmação de M. Foucault: "É preciso distinguir as relações de poder das relações de comunicação que transmitem uma informação através de uma língua, um sistema de signos ou através de outro meio simbólico. Sem dúvida, comunicar é uma certa maneira de agir sobre o outro ou os outros. Mas a produção e o colocar em circulação elementos significativos podem ter por objetivo ou por consequência efeitos de poder (...) ". (FOUCAULT, 1994, p. 233, tradução própria).

ALMEIDA, C. A. 0 poder dos discursos do patronato portuense nas sessões comemorativas de 
Linha D'Água (Online), São Paulo, v. 30, n. 1, p. 69-87, jun. 2017

engenheirismo"; 3. o patrão como "gestor" (MONTEIRO, 2015, p. 89-129). Por razões de síntese e de pertinência do argumento apresentado, no presente trabalho consideraremos quatro discursos que perspectivam o patrão como "engenheiro".

\section{A pedagogia dos discursos e a construção enunciativa das notícias de Aniversário da Associação Industrial Portuense}

Um discurso constrói um sistema de avaliações do mundo e instaura uma dimensão ilocutória (FONSECA, 1992, p. 316). As propostas de análise das dimensões interativas (ou coerência pragmático-funcional) que se projetam nos discursos (FONSECA, 1992, p. 238) permitem conceber uma pedagogia dos discursos (Fonseca, 1992, p. 315) aberta à pluralidade destes últimos.

Tomando por referência o discurso das notícias dos Aniversários da AIP que descrevem a cerimónia de "distribuição de prémios a operários e a estudantes", o quadro interacional (GOFFMAN, 1987) construído nestes discursos é sempre iniciado com a indicação dos participantes: oradores, homenageados e convidados. $\mathrm{Na}$ sequência de introdução, há a indicação da data e dos atores sociais presentes na sessão apresentada com o epíteto de "festa comemorativa". Salienta-se a distribuição de prémios a "operários da indústria fabril nortenha", descrevendo-se esta atribuição de prémios com o adjetivo "costumada" e realça-se "a solenidade" do evento, elencando-se as individualidades que estão presentes na cerimónia:

(1) "Com a solenidade dos anos anteriores, realizou-se na noite de 3 de Maio, no salão nobre da Associação Industrial Portuense, a festa comemorativa do 101. ${ }^{\circ}$ aniversário da sua fundação, que coincidiu com a costumada distribuição de prémios a operários da indústria fabril nortenha e a estudantes da Faculdade de Engenharia, Instituto Industrial e Escolas industriais do Porto e de Gaia, tendo ainda a realçá-la a presença do ilustre reitor da Universidade do Porto, sr. dr. Amândio Tavares, em representação do sr. Ministro da Educação Nacional (...)"(101º. Aniversário da AIP, 1950).

(2) "Numa sessão solene, efectuada na noite de 4 de Maio, na nossa sede, a Associação Industrial Portuense comemorou o $115 .^{\circ}$ aniversário da sua fundação, 
Linha D'Água (Online), São Paulo, v. 30, n. 1, p. 69-87, jun. 2017

encerrando, ao mesmo tempo, um ciclo de conferências, que ali se vinha efectuando, sobre 'Desenvolvimento Económico e Relações Económicas Internacionais"” (115. . Aniversário da AIP, 1964).

A esta introdução, segue-se a apresentação dos Oradores que, sucessivamente, irão proferir os discursos e que farão parte da comemoração de aniversário, sendo os adjetivos, nestes discursos, regularmente, antepostos aos nomes: "abalizado professor", "interessante conferência", "flagrante oportunidade". Atentemos, então, nos seguintes exemplos:

(3) "e do abalizado professor da Faculdade de Engenharia, sr. dr. Antão de Almeida Garrett, que pronunciou uma interessante conferência, subordinada ao tema de flagrante oportunidade: 'A agricultura e a Indústria na região do Porto"' (101. Aniversário da AIP, 1950).

$\mathrm{Na}$ retórica deste discurso de notícia de comemoração de aniversários da AIP, o jornalista faz constante uso de adjetivos antepostos ao nome:

(4) "Eng. ${ }^{\circ}$ Antão de Almeida Garrett que pronunciou a conferência que reproduzimos na íntegra, documentada com curiosos e expressivos gráficos e mapas" (101. Aniversário da AIP, 1950).

A apresentação dos participantes faz parte do corpo da notícia revelando o cumprimento de um protocolo cerimonial que apresenta a indicação de que cada participante elencado representa uma alta individualidade do Estado:

(5) "Assumiu a presidência da sessão, o sr. prof. Doutor Amândio Tavares, que tinha à sua direita os srs. Dr. Henrique Cabral, representante do sr. subsecretário de Estado das Corporações e Previdência Social, (...) à esquerda os srs. João de Almeida Campos, representando o sr. governador civil do distrito (...)" (101º. Aniversário da AIP, 1950). 
Linha D'Água (Online), São Paulo, v. 30, n. 1, p. 69-87, jun. 2017

Nestas notícias de comemoração é frequente que a sessão tenha um discurso de abertura e um discurso de entrega de prémios:

(6) "Aberta a sessão, foi dada palavra ao sr. eng. ${ }^{\circ}$ Mário Borges, presidente da Associação Industrial Portuense, que pronunciou o seguinte discurso: (...)” (101. Aniversário da AIP, 1950).

Regularmente, o discurso do orador principal é apresentado na íntegra, sendo relativo aos prémios atribuídos aos operários e estudantes do Ensino Técnico, realçando-se o seu mérito através do uso do adjetivo no grau superlativo relativo de superioridade como forma de intensificação do discurso:

(7) "operários e a estudantes dos nossos centros fabris e das escolas de ensino técnico que mais se evidenciaram perante os seus patrões ou professores" (101. Aniversário da AIP, 1950).

No exemplo (7), o uso da primeira pessoa do plural (plural inclusivo) destaca o sentido de pertença a uma comunidade, salientando-se a visão da fábrica como um "centro": "os nossos centros fabris".

\section{0 macroato de elogio: mitigadores e intensificadores ao serviço da persuasão}

Nestas notícias, ocorrem asserções mitigadas com marcadores de vagueza e com quantificadores existenciais que tornam a quantidade vaga (mas nunca coincidindo com a totalidade) ao serviço de uma estratégia argumentativa de persuasão:

(8) "uma sessão solene, durante a qual se distribuem alguns prémios a operários e estudantes dos nossos centros fabris e das escolas de ensino técnico" (101º. Aniversário da AIP, 1950). 
Linha D'Água (Online), São Paulo, v. 30, n. 1, p. 69-87, jun. 2017

Os mitigadores, como "alguns", têm um efeito retórico de persuasão. De acordo com Derek Edwards (2000), os mitigadores em apreço, apesar de constituírem atenuadores, são retoricamente e interacionalmente mais fortes (EDWARDS, 2000, p. 354). Fazendo parte de uma "atividade argumentativa (retórica) e estratégica de minimização" (BRIZ, 2013: 284), estes mitigadores minimizam a força ilocutória dos atos de asserção. Expressando valores modais epistémicos no domínio do incerto (CAFFI, 2000, p. 96), os mitigadores constituem, sobretudo, uma forma de persuasão do alocutário (BRIZ, 2013, p. 284). Neste caso específico, a asserção apresenta um quantificador existencial que reduz a quantidade de prémios vaga, não especificada, estando ao serviço da lei da modéstia que permite convencer o auditório do discurso e os leitores da revista de que o que importa não é o prémio atribuído, mas o valor dos operários e dos estudantes na sua totalidade, como corpo único da fábrica, que se quer realçar. Trata-se de uma clara estratégia de intensificação do valor "intelectual" e "braçal", por um lado, dos futuros engenheiros e, por outro lado, dos operários, minimizando-se os prémios materiais. No âmbito desta estratégia de persuasão do alocutário, o constante uso da primeira pessoa do plural permite convencer, argumentativamente, o auditório de que a atribuição de prémios visa incentivar ao progresso e ao trabalho na indústria:

(9) “É fácil apercebermo-nos da satisfação que sentimos quando nós, os industriais, de ano a ano, vimos distribuir estes prémios e porque, sentindo a necessidade de acompanhar o progresso da técnica, não nos furtamos a emprestar um certo estímulo, com o objectivo de melhorar o nosso desempenho industrial" (101º. Aniversário da AIP, 1950).

O uso do pronome da primeira pessoa do plural "nós" tem como aposto "os industriais", permitindo, estrategicamente, apelar a uma classe e ancorar o discurso na legitimação da produção de atos de asserção sobre a ação dos industriais que distribuem prémios aos operários e fazem discursos de comemoração de louvor e estímulo ao trabalho. Com efeito, os locutores do discurso realizam identidades situadas (Zimmerman, 1998) orientadas pelas posições institucionais que assumem. A realização do ato de justificação "e porque, sentindo a necessidade de acompanhar o progresso 
Linha D'Água (Online), São Paulo, v. 30, n. 1, p. 69-87, jun. 2017

da técnica", seguido da asserção na forma negativa "não nos furtamos a emprestar um certo estímulo", constitui uma forma argumentativa de demonstrar a pertinência do macroato de elogio à atribuição de prémios. A justificação em apreço realça lugares comuns frequentes na época, como o emprego de sintagmas preposicionais como "progresso da técnica". O uso da forma negativa "não nos furtamos" tem por implicação a afirmação de que "realizamos sem fugir", pondo em destaque a coragem e o valor alto da ação de atribuir prémios como estímulo ao trabalho e contribuindo, assim, para a intensificação do ato de elogio à ação dos industriais. Pelo facto de o discurso ser intensificador do valor positivo dos industriais ocorre, de seguida, a produção de um discurso vago, dominado pela lei da modéstia, com a expressão "um certo estímulo". Com efeito, o uso do atenuador e/ou mitigador como "um certo" é seguido de uma nova justificação que, argumentativamente, legitima a ação dos industriais com uma nova produção de um plural inclusivo: "com o objectivo de melhorar o nosso desempenho industrial”. Esta intervenção constitui uma estratégia argumentativa para demonstrar o valor do bom desempenho não só dos operários e estudantes, mas também o alto valor dos industriais (patrões), constituindo uma estratégia argumentativa de valorização da ação destes últimos, como homens cuja esfera de ação constitui um estímulo ao trabalho.

Ocorrem também, no texto argumentativo de discurso de opinião, conectores específicos como "em suma", seguidos de nomes no diminutivo que fazem parte de um léxico que expressa o princípio da modéstia. Este constitui, igualmente, uma força de persuasão do discurso do orador. Integra-se neste princípio de modéstia o uso do lexema "nótula" no seguinte parágrafo:

(10) “É, em suma, uma nótula, à qual se deve atribuir foros de boa e qualificada recompensa, conseguida pelos nossos associados” (101․ Aniversário da AIP, 1950).

O lexema "nótula" é associado ao lexema "recompensa". Este último é qualificado com adjetivos com valor axiológico positivo ("boa e qualificada recompensa") e cuja ação se atribui agora aos associados da AIP. 
Linha D'Água (Online), São Paulo, v. 30, n. 1, p. 69-87, jun. 2017

O discurso do orador realça estrategicamente o valor alto das ações realizadas pelos industriais em contraste com as "dificuldades" que são sempre vistas como "ensinamentos necessários, com o objectivo de as sentirmos fortemente atenuadas", destacando, argumentativamente, o valor positivo de apelo ao trabalho que os industriais desenvolvem para aumentar a produtividade nas fábricas.

Compreende-se, pois, que, ao serviço da exaltação e elogio da ação dos operários e estudantes, no quadro enunciativo da sessão solene, haja o desenvolvimento de uma estratégia argumentativo-retórica de uso de intensificadores do discurso (destacados a itálico):

(11) "Estamos, por isso mesmo, sempre decididos a trabalhar em proveito da consolidação da nossa estrutura económica, com uma labuta mais intensa e para o maior engrandecimento da nossa já desenvolvida actividade industrial" (101º. Aniversário da AIP, 1950).

Regularmente, como referimos anteriormente, os intensificadores coocorrem com atenuadores (como "por certo") como forma de cumprimento do princípio da modéstia:

(12) "Continuamos confiantes, embora solícitos em apresentar os males que mais directamente nos afectam, não faltando, por certo, nem a experiência, nem as virtudes da massa industrial para não só corresponder aos trabalhos necessários, como para lançar mão de mais iniciativas onde possam frutificar, num ambiente mais esclarecido, os empreendimentos dos nossos industriais e a mão de obra nacional" (101º. Aniversário da AIP, 1950).

O princípio de modéstia possibilita o envolvimento do auditório através de uma clara estratégia de apelo ao consenso ao mesmo tempo que se exaltam as "virtudes" dos trabalhadores e dos industriais. Em (12), ocorrem lexias como "massa industrial" associadas às "virtudes"; os "trabalhos" são qualificados como "necessários" e os verbos como "frutificar" são expressos em asserções com valor axiológico 
Linha D'Água (Online), São Paulo, v. 30, n. 1, p. 69-87, jun. 2017

positivo que destacam o valor alto do trabalho: “(...) frutificar (...) os empreendimentos dos nossos industriais e a mão de obra nacional”.

Por fim, na conclusão destes discursos, ocorrem sequências da autoria do jornalista que remetem para o auditório do discurso e descrevem as palmas:

(13) “O orador foi, ao terminar, muito aplaudido"(101. Aniversário da AIP, 1950). (14) "Ao terminar foi o orador calorosamente aplaudido"(106. ${ }^{\circ}$ aniversário da AIP, 1955).

\section{Estratégias argumentativas (retóricas): a retórica do "engenheirismo"}

Nos discursos proferidos por oradores nas sessões comemorativas de aniversário da AIP, é frequente o uso de metonímias como "braço boçal" para se referir a "operários sem especialização" e o segmento "braços sobrantes" remete, por contiguidade com o referente do mundo, para "desempregados":

(15) "O braço boçal por baixo preço não pode resolver as nossas dificuldades. É preciso que seja destro e consciente” (101. Aniversário da AIP, 1950).

Este uso da metonímia tem como função a intensificação do discurso, contribuindo para salientar o que é dito:

(16) "Passando à oferta e procura de mão-de-obra, não se pode pôr a sua falta numa região de aflitivo excedente demográfico. Pelo contrário, estamos preocupados em descobrir meios que permitam ocupar tantos braços sobrantes" (101. Aniversário da AIP, 1950).

Dado o contexto histórico da época em Portugal, os "braços que hão-de sobrar" estariam destinados às colónias, ancorando o discurso numa argumentação que concebia a colonização como uma forma positiva de dar emprego a muitos trabalhadores: 
Linha D'Água (Online), São Paulo, v. 30, n. 1, p. 69-87, jun. 2017

(17) "E para os braços que, pelo ritmo do crescimento da população, ainda hãode sobrar, preparemos nós mesmo uma colonização intensa dos territórios ultramarinos, em complemento da nossa própria economia regional" (101 . Aniversário da AIP, 1950).

Estes operários sem trabalho são negativamente perspectivados e, implicitamente, encara-se de modo positivo os operários que têm trabalho:

(18) "Quem quer que não trabalhe acaba por desaparecer; é repelido como inútil e indesejável” (106. ${ }^{\circ}$ aniversário da AIP, 1955).

Estes "braços sobrantes" constituídos por trabalhadores sem especialização técnica são perspectivados de modo negativo para que se possa realçar, argumentativamente, o valor dos trabalhadores especializados. Com efeito, nos discursos que os oradores proferem na cerimónia e que são transcritos na revista $A$ Indústria do Norte, assiste-se à constante convocação de uma doxa para estabelecer um movimento contra-argumentativo que contraria o que se diz de modo a apelar à mudança operada na visão do operário, que passa a ser visto como trabalhador especializado e não apenas como mão de obra não qualificada:

(19) "A produção - e é esse o nosso mais grave problema - não se resolve com muitos homens. Já lá vai o tempo em que se dizia: que a muita gente é que faz a guerra. A eficiência da produção, em qualidade e preço, exige saber e apetrechamento" (101º. Aniversário da AIP, 1950).

Neste exemplo (19), contraria-se a doxa de que "muita gente faz a guerra" para se argumentar a favor da leitura de que é mais importante ter poucos trabalhadores qualificados do que ter muitos trabalhadores sem qualificação na fábrica.

Assim, os oradores realçam no discurso, através de um processo metonímico, a importância de alimentar e empregar "novos braços" para se referirem aos trabalhadores, integrando-os nos diversos sectores da sociedade e não apenas na indústria: 
Linha D'Água (Online), São Paulo, v. 30, n. 1, p. 69-87, jun. 2017

(20) "A Agricultura e a Indústria, tão interligadas na sua economia, terão de tomar parte importante nessa tarefa de elevar o nível de vida da população activa e ocupar, na medida do possível, os novos braços que precisam de trabalho para viver" (101. Aniversário da AIP, 1950).

Para destacarem o papel dos novos operários com qualificação, destaca-se no discurso a importância do ensino:

(21) "Muitos industriais teriam grande vantagem numa mais forte colaboração com o ensino" (101. Aniversário da AIP, 1950).

Faz parte desta retórica do "engenheirismo" a referência à importância da técnica e realça-se a formação técnica e moral tanto do patrão engenheiro como do operário especializado, como podemos verificar na seguinte asserção argumentativa:

(22) "A valorização social dos nossos trabalhadores tem de partir duma melhor preparação técnica e moral, quer do operário quer do dirigente" (101․ Aniversário da AIP, 1950).

Destaca-se neste binómio a importância do amor ao trabalho e ao estudo através de atos de votos:

(23) "Bem hajam, portanto, V. Ex.as em galardoarem alguns dos que mostraram verdadeiro amor ao trabalho e ao estudo" (101. Aniversário da AIP, 1950).

Estes atos de votos são seguidos de asserções que permitem, por implicitação, justificar a atribuição de prémios:

(24) “São prémios que representam justiça para uns e estímulo para todos" (101. Aniversário da AIP, 1950). 
Linha D'Água (Online), São Paulo, v. 30, n. 1, p. 69-87, jun. 2017

No estilo da retórica do "engenheirismo", assiste-se sempre ao movimento de apelo à colaboração do auditório com o uso de expressões que relevam do cumprimento do princípio da modéstia seguido de um movimento de intensificação da caracterização como forma de dar relevo aos atos ilocutórios de elogio e louvor da ação dos industriais e operários especializados. Verificamos, assim, o uso de adjetivos antepostos ao nome como a expressão "despretensiosa palestra" que remete para o princípio da modéstia e ocorrem expressões que apresentam intensificadores (a itálico) como o uso de segmentos como "um excedente demográfico grande". Assiste-se também à construção de um discurso escrito cuidado, repleto de sensações: "verdura purificadora dos arvoredos" (101. Aniversário da AIP, 1950).

Também frequente é o uso de metáforas que remetem para um coletivo social próprio da fábrica: “uma colmeia de gente” (101º. Aniversário da AIP, 1950).

A estrutura destas notícias apresenta sempre um fecho em forma de conclusão que remete para os aplausos próprios da cerimónia de audição de um discurso comemorativo com teor elogioso. Estes aplausos são sempre qualificados com adjetivos intensificadores do ato de aplaudir (apresentados em itálico):

(25) "Ao concluir a sua tão judiciosa como lúcida dissertação, em que se debateu numa tese de reconhecido alcance económico e social, foi o conferente distinguido com nutridas e prolongadas salvas de palma" (101‥ Aniversário da AIP, 1950).

(26) "O orador ouviu, no final, calorosas salvas de palma" (115. o aniversário da Associação Industrial Portuense).

(27) "O orador ouviu no final calorosos aplausos"(103. o aniversário da Associação Industrial Portuense).

\section{Ritualização das práticas discursivas}

Os textos publicados na revista "A Indústria do Norte" apresentam as alocuções de oradores representantes do patronato que são proferidas em sessões solenes. Nestas alocuções é demonstrada a posição dos dirigentes patronais que, nos discursos selecionados, revelam a imagem do operário como "braço" que tem de desenvolver 
Linha D'Água (Online), São Paulo, v. 30, n. 1, p. 69-87, jun. 2017

uma formação especializada, estando neste caso também patente a imagem do "patrão como técnico" que "visa patrocinar o industrialismo" e que demonstra "a crença nas virtudes da técnica e da indústria” (MONTEIRO, 2015, p. 96). Com efeito, nestes discursos, "o industrialismo propõe uma solução técnica para os problemas sociais, tanto na fábrica como na nação" (MONTEIRO, 2015, p. 115). Perante um discurso do orador que analisa o efeito do nacionalismo, ideologicamente marcado e justificado por motivos de reabilitação económica, ocorre um certo distanciamento do jornalista da revista em relação ao que é proferido em forma de discurso indireto e de comentário (em itálico):

(28) "Prosseguindo, observou que o aparecimento do conceito nacionalista agravou ainda mais a situação, embora esse ponto de vista, adoptado por vários governos, fosse apenas uma premissa lógica para a exequibilidade dos seus desejos de reabilitação económica. Mas tudo isso tem de ser encarado pelo ângulo particular de quem estuda e analisa os assuntos" (115. ${ }^{\circ}$ aniversário da Associação Industrial Portuense, 1964).

No quadro de uma estratégia argumentativa ocorrem máximas que constituem salvaguardas da posição do jornalista que constitui a voz da notícia:

(29) "Aos especialistas competirá exame mais profundo do assunto, e, a quem de direito, dar a orientação a seguir se o caso vai mal" (101. Aniversário da AIP, 1950).

Ocorrem verbos como "esmiuçar", "dissecar", lexemas próprios da época:

(30) "Continuando a esmiuçar a situação dessa altura, o orador, ainda dentro do mesmo ponto de vista manifestado antes, disse a certa altura (...)" (115. ${ }^{\circ}$ aniversário da Associação Industrial Portuense, 1964).

(31) "Mais adiante, o sr. Dr. Mesquita Gabriel derivou para o campo do proteccionismo novamente, que procurou dissecar através da enumeração das 
Linha D'Água (Online), São Paulo, v. 30, n. 1, p. 69-87, jun. 2017

consequências que ele teria suscitado" (115. ${ }^{\circ}$ aniversário da Associação Industrial Portuense, 1964).

Como referimos anteriormente, a adjetivação é frequente nestes discursos e o uso do plural inclusivo intensifica o que se diz e constitui uma estratégia de apelo ao consenso: as "estatísticas elucidativas", o "nosso ultramar".

Os votos são sempre intensificados (em itálico):

(32) "após o que se referiu a um outro aspecto da acção educativa desempenhada pela Associação Industrial Portuense, o da instituição anual de doze bolsas de estudo para os filhos daqueles operários mais necessitados, acção que fazia votos se prolongasse sem desfalecimentos" (115. ${ }^{\circ}$ aniversário da Associação Industrial Portuense, 1964).

Nas sessões comemorativas, destaca-se também, argumentativamente, o valor do trabalho:

(33) "O trabalho enche a vida do homem e é o primeiro factor da obra da civilização. Sem actividade produtora, o homem cairia na degradação e na esterilidade do ócio e a cultura estaria condenada a desaparecer" (105. a aniversário da AIP,1954).

(34) "O trabalho é uma escola de dedicação como de justiça: é a própria vida e a vida um perpétuo trabalho de forças químicas e mecânicas, como observa um célebre escritor" (106. ${ }^{\circ}$ aniversário da AIP, 1955).

O trabalho é comparado ao movimento que existe no Universo e na natureza e esta comparação é expressa através de uma pergunta retórica que confirma o implícito conversacional de que o Universo é uma "oficina imensa":

(35) "Não é o Universo uma oficina imensa em que nunca se descansa, em que todos os dias os infinitamente pequenos operam labor gigantesco, em que a 
Linha D'Água (Online), São Paulo, v. 30, n. 1, p. 69-87, jun. 2017

matéria actua, fabrica, cria sem parar desde os simples fermentos às criaturas mais perfeitas?" (106. ${ }^{\circ}$ aniversário da AIP, 1955).

A esta pergunta retórica segue-se um macroato de explicitação desta comparação entre o trabalho e a natureza:

(36) “(...) trabalham os rios correndo pelos vales amenos, trabalham os mares fazendo rolar as suas vagas de um para outro continente (...)"(106. ${ }^{\circ}$ aniversário da AIP, 1955).

Há a realização de votos e de elogios aos estudantes e trabalhadores que se estendem à Pátria que os acolhe:

(37) "Bendigamos, pois, o trabalho, propulsor da ordem e do progresso; e louvemos os trabalhadores - estudantes e operários - que hoje aqui premiamos é que, dignificando-se a si próprios, também honram a Pátria que os viu nascer" (106. ${ }^{\circ}$ aniversário da AIP, 1955).

A visão da máquina é apresentada com valor axiológico positivo, destacandose, no entanto, que o louvor é feito, sobretudo, ao operário e ao seu esforço:

(38) "Premiando os trabalhadores, não idolatramos a máquina. Louvamos, sim, o esforço do operário, a sua conduta irrepreensível, o seu amor ao trabalho, a sua perícia profissional e o culto da sua arte ou do seu ofício" (105. a aniversário da AIP, 1954).

São destacados os estudantes (futuros engenheiros, por exemplo) e os operários especializados, os primeiros são referidos como "trabalhadores do espírito" e os segundos são referenciados como "trabalhadores manuais" ou "trabalhadores da ferramenta": 
Linha D'Água (Online), São Paulo, v. 30, n. 1, p. 69-87, jun. 2017

(39) "E esta festa da Associação Industrial Portuense é também uma vitória do trabalho, em que duplamente são galardoados os trabalhadores do espírito e os trabalhadores manuais - os estudantes e os operários, a quem, nesta ocasião, quero dirigir sinceramente as mais efusivas saudações" (105 . aniversário da AIP, 1954).

(40) "Vemos felizes os homenageados, porque sentem, com igual orgulho, que souberam corresponder a tão simpática iniciativa, cumprindo digna e devotamente o seu dever de trabalhadores da ferramenta e do espírito" (103. ${ }^{\circ}$ aniversário da AIP, 1952).

\section{Conclusão}

Os discursos proferidos pelos representantes do patronato portuense nas sessões comemorativas da AIP apresentam elementos discursivos que se inscrevem em movimentos argumentativo-retóricos que visam a persuasão. Por um lado, o uso dos intensificadores (ECFs) está ao serviço da eficácia e da argumentação, apelando ao consenso. Inscrevem-se nesta estratégia de intensificação do discurso os seguintes dispositivos linguísticos: o emprego de adjetivos como "[interesse] palpitante", "simpática [iniciativa]”, "interessante [conferência]" "flagrante [oportunidade]”, "[estatísticas] elucidativas", "nutridas e prolongadas [palmas]", "calorosas [palmas]", "curiosos e expressivos [gráficos]”, "despretensiosa [palestra]”; o uso estratégico da negação; o recurso à metáfora em descrições e em atos de natureza sequencial como o macroato de explicitação, bem como o funcionamento de perguntas retóricas. Por outro lado, mitigadores como "por certo", bem como quantificadores como "alguns", assim como a metonímia ("braço boçal", "os novos braços", "braços sobrantes") fazem parte dos atenuadores que visam persuadir o ouvinte/destinatário destes discursos.

O discurso nestes contextos comemorativos apresenta a construção de "social schemas" (GIBBS, 1985, p. 98) convencionais com estratégias de credibilização, de apelo ao consenso e inúmeros atos de elogio, revelando um discurso emotivo (PLANTIN et al., 2000) e a construção de um "saber compartilhado" (Kayser, 1988, p. 142) entre os representantes do patronato, o auditório e os leitores da revista constituídos pelos associados da AIP. 
Linha D'Água (Online), São Paulo, v. 30, n. 1, p. 69-87, jun. 2017

Os representantes dos patrões põem em jogo um dispositivo argumentativo de convocação de uma doxa partilhada pela comunidade de discurso (GUMPERZ, 1989). Esta estratégia de argumentação visa a persuasão e é reveladora de uma tomada de posição específica de um locutor representativo do patronato portuense da época.

Com efeito, no dizer de P. Bourdieu, todas as formas de expressão rituais e as estratégias “(...) configuram uma certa pretensão para a luta simbólica como poder socialmente reconhecido de impor uma visão do mundo social, isto é, as divisões do mundo social" (BOURDIEU, 2001, p. 156).

\section{Referências}

ANTAKI, C.; WIDDICOMBE, S. (eds.). Identities in talk. London: Sage, 1998.

BOURDIEU, P. Langage et pouvoir symbolique. Paris: Fayard/Seuil, 2001.

BRIZ, A. A atenuação e os atenuadores: estratégias e táticas. In: Linha D'Água, n. 26 (2), 2013, p. 281-314.

CAFFI, C. Aspects du calibrage des distances émotives entre rhétorique et psychologie. In: PLANTIN, C. et al., (orgs.). Les émotions dans les interactions. Lyon: Presses Universitaires de Lyon, 2000, p. 89-104.

EDWARDS, D. Extreme case formulations: softeners, investment and doing nonliteral. Research on language and social interaction, 33, 4, 2000, p. 347-373.

FONSECA,J. Linguística e texto/discurso - teoria, descrição, aplicação. Lisboa: Ministério da Educação / Instituto de Cultura e Língua Portuguesa, 1992.

FOUCAULT, M. Le sujet et le pouvoir. In: FOUCAULT, M. Dits et Écrits (1954-1988). IV. Gallimard: Bibliothèque des Sciences Humaines, 1994.

GIBBS, R. W. (1985) Situational conventions and requests. In Forgas, Joseph P. (ed.). Language and social situations. New York: Springer-Verlag, 1985, p. 97-110.

GOFFMAN, E. Façons de parler. Paris: Minuit, 1987. 
Linha D'Água (Online), São Paulo, v. 30, n. 1, p. 69-87, jun. 2017

GUMPERZ, J. Sociolinguistique interactionnelle. Une approche interprétative. La Réunion: L'Harmattan, 1989.

KAYSER, H. Quelques aspects de la comprehension et de la production du langage dans l'interaction verbale: approche cognitive et approche conversationnelle. In Cosnier, J.; Gelas, N.; Kerbrat-Orecchioni, C. (ed.). Échanges sur la conversation. Paris: CNRS, 1988, p. 135-174.

KERBRAT-ORECCHIONI, C. La notion de 'place' interactionnelle ou les taxèmes qu'est que c'est que ça ? In Cosnier, J.; Gelas, N.; Kerbrat-Orecchioni, C. (ed.) Échanges sur la conversation. Paris: CNRS, 1988, p. 185-198.

KERBRAT-ORECCHIONI, C. Introducing polylogue. Journal of pragmatics, vol. 36, 1, 2004, p. 1-24.

MONTEIRO, B. Homens industriosos. Uma sociologia histórica das tomadas de posição do patronato portuense (1945-1974). Porto: Fundação Eng. António de Almeida, 2015.

PLANTIN, C.; DOURY, M.; TRAVERSO, V. (orgs.) Les émotions dans les interactions. Lyon: Presses Universitaires de Lyon, 2000.

VERSCHUEREN, J. El regreso de la Pragmática al significado: comentarios sobre la dinámica de la comunicación, los grados de prominencia y la transparencia comunicativa. In: Royo, L. M.; Whittaker, R. Poder - decir o el poder de los discursos. Madrid: Arrecife, Ediciones de la Universidad Autónoma de Madrid, 1998, p. 235-279.

WETHERELL, M.; TAYLOR, S.; YATES, S. J. (eds.). Discourse theory and practice. A reader. London: Sage, 2001.

WORTHAM, S.; LOCHER, M. Voicing on the news: an analytic technique for studying media bias. In: Text 16, 4, 1996, p. 557-585.

ZIMMERMAN, D. H. Identity, context and interaction. In ANTAKI, C.; WIDDICOMBE, S. (eds.). Identities in talk. London: Sage, 1998, p. 87-106.

Recebido: 28/05/2017. Aprovado: 10/08/2017.

ALMEIDA, C. A. 0 poder dos discursos do patronato portuense nas sessões comemorativas de 